\title{
Tax Competition, Public Good Provision, and Income Redistribution
}

\author{
Toshihiro Ihori $^{\mathrm{a}^{*}}$ and C.C. Yang ${ }^{\mathrm{b} \dagger}$ \\ ${ }^{a}$ University of Tokyo \\ ${ }^{b}$ Academia Sinica; National Chengchi University; National Sun Yat-sen University
}

\begin{abstract}
This paper considers a tax competition model in which regional government activities include income redistribution as well as public good provision. To incorporate the regional government function of income redistribution, we extend the tax system from the stylized proportional capital income tax to the linear capital income tax with a uniform lump-sum grant: the revenue collected from capital taxation in each region is used not only to provide the regional public good but also to offer a uniform lump-sum grant to each individual in the region. In contrast to Hoyt's (1991) finding that the extent to which public goods are undersupplied is monotonically increasing in the number of competing regions, we show that, regardless of the number of competing regions, all heterogeneous individuals concur with each other on the first-best provision of public goods; on the other hand, the size of income redistribution is monotonically decreasing in the number of competing regions.
\end{abstract}

JEL Classification: D72, F20, H41

Keywords: tax competition, public goods, income redistribution

\section{Introduction}

A fundamental result in the literature on tax competition is that interregional tax competition for mobile capital generates fiscal externalities and tends to result in an

\footnotetext{
* Department of Economics, University of Tokyo, Hongo, Tokyo 113-0033, Japan. Email: ihori@e.u-tokyo. ac.jp.

${ }^{\dagger}$ Corresponding author, Institute of Economics, Academia Sinica, Nankang, Taipei 115, Taiwan. Email: ccyang@econ.sinica.edu.tw We are grateful to Jay Wilson and an anonymous referee for their helpful comments on an earlier version of this paper.
} 
undersupply of public goods in a region. This result is originally articulated by Oates (1972) and formally modeled by Wilson (1986) and Zodrow and Mieszkowski (1986). ${ }^{1}$

In an important contribution, Hoyt (1991) shows that the extent to which public goods are undersupplied is monotonically increasing in the number of competing regions. Following Wilson and Wildasin (2004), an increase in the number of competing regions can be viewed as "increased" tax competition. Thus, Hoyt's finding suggests that "increased" interregional tax competition will worsen the undersupply of public good provision in a region.

On the basis of his finding, Hoyt (1991, p. 130) concludes:

"The existence of wasteful tax competition suggests that the optimal number of jurisdictions is one, thereby eliminating the externalities created by capital taxation. The traditional Tiebout literature argues that having many independent jurisdictions promotes efficiency and taste stratification by increasing the competition among jurisdictions. Thus, a tradeoff is faced, more jurisdictions increase the sorting of residents but at a cost of decreasing the public service provision because of tax competition."

Hoyt employs a standard tax competition model in which regional government activities are confined to public good provision only. This setup is obviously counterfactual. Indeed, existing data clearly indicate that income redistribution constitutes the most dramatic rise in regional government activities during the past century (Tanzi and Schuknecht, 2000).

In this paper we extend the Hoyt model to a more realistic world in which regional government activities include not only public good provision but also income redistribution. The stylized tax system considered in tax competition models is the proportional capital income tax. To incorporate the regional government function of income redistribution, we extend the stylized tax system from the proportional to the linear capital income tax with a uniform lump-sum grant: the revenue collected from capital taxation in each region is used not only to provide the regional public good but also to offer a uniform lump-sum grant to each individual in the region. In contrast to Hoyt's finding, we show that, regardless of the number of competing regions, all heterogeneous individuals concur with each other on the first-best provision of public goods; on the other hand, the size of income redistribution is monotonically decreasing in the number of competing regions. Our result suggests that the tradeoff with more jurisdictions is not at a cost of decreasing public service provision as in Hoyt (1991), but at a cost of decreasing income redistribution if more redistribution is desirable.

\footnotetext{
${ }^{1}$ This fundamental result is stated as Proposition 4.1 in Wellisch (2000, p. 64) and as Proposition 4.2 in Haufler (2001, p. 65). See Wilson (1999), Wilson and Wildasin (2004), and Fuest et al. (2005) for surveys of the tax competition literature.
} 


\section{Model}

Our model of the economy is standard in the tax competition literature ${ }^{2}$ with the two peculiarities: (i) there are heterogeneous rather than homogeneous individuals, and (ii) regional government activities include income redistribution as well as public good provision. These two peculiarities are obviously intertwined. There would be no need for the government function of income redistribution if people were homogeneous.

Consider an economy in which there are $n$ identical regions, where $n \in\{1, \ldots, \infty\}$. Each region is inhabited by $N$ individuals. There are two factors of production: an interregional immobile factor and a perfectly mobile factor. This is a caricature of the real world situation in which some factors have a much higher interregional mobility than others. Following the previous literature, we will refer to the immobile factor as "labor" and to the mobile factor as "capital". Each individual in each region has the same claim to immobile labor, but unequal claims to mobile capital. Specifically, individual $j$ in region $i$ supplies $1 / N$ units of labor and $\bar{k}_{i j}$ units of capital. This inequality feature in endowment is again a caricature of the real world situation in which capital incomes are more unequally distributed than labor incomes. ${ }^{3}$

Let $\bar{k}_{i}=\sum_{j} \bar{k}_{i j}$. Denoting the amount of capital employed in region $i$ by $k_{i}$, capital market clearing requires:

$$
\sum_{i} k_{i}=\sum_{i} \bar{k}_{i}
$$

All regions produce a single private good whose price is normalized to unity. This private good can either be consumed directly as a private commodity, $c$, or be used to provide the regional public service, $g$. One unit of the private good produces one unit of the public service. The production in each region is given by $f\left(k_{i}\right)$ with $f^{\prime}\left(k_{i}\right)>0$ and $f^{\prime \prime}\left(k_{i}\right)<0$, where a unit of the labor input in the region is suppressed. All markets are assumed to be perfectly competitive.

Each region levies a source tax at rate $t_{i}$ on each unit of capital employed within its region. Perfectly mobile capital implies:

$$
f^{\prime}\left(k_{i}\right)-t_{i}=r\left(t_{1}, \ldots, t_{n}\right) \quad \forall i
$$

where $r$ is the after-tax rate of return on capital, which depends on $t_{1}, \ldots, t_{n}$ and is equalized across the economy. Using (1)-(2) and the assumption that all regions are identical, we have ${ }^{4}$ :

$$
\frac{\partial r}{\partial t_{i}}=\frac{-1}{n} \forall i
$$

${ }^{2}$ The model is built on Hoyt (1991). As noted by Hoyt, his model follows that of Wildasin (1988). It is a textbook, workhorse model of tax competition; see, for example, Wellisch (2000, section 4.1) and Haufler (2001, section 4.3).

${ }^{3}$ For empirical evidence, see Davies and Shorrocks (2000). One may incorporate labor as well as capital inequality into the model. However, it yields few further insights as far as this paper is concerned.

${ }^{4}$ See Hoyt (1991). 


$$
\begin{aligned}
& \frac{\partial k_{i}}{\partial t_{i}}=\frac{1-(1 / n)}{f^{\prime \prime}\left(k_{i}\right)} \forall i \\
& \frac{\partial k_{i}}{\partial t_{-i}}=\frac{-(1 / n)}{f^{\prime \prime}\left(k_{i}\right)} \forall i,-i
\end{aligned}
$$

where $-i$ denotes any region other than region $i$.

Let $u_{i j} \equiv u\left(c_{i j}, g_{i}\right)$ denote the preferences of individual $j$ in region $i$ over the private good $c$ and the public service $g$. We shall work with the quasilinear form: $u\left(c_{i j}, g_{i}\right)=c_{i j}+v\left(g_{i}\right)$ with $v^{\prime}>0$ and $v^{\prime \prime}<0$. For one thing, this form has become standard in the literature on public goods. ${ }^{5}$ Perhaps more importantly, the quasilinear form makes our work directly comparable with a large tax competition literature on the efficiency problems associated with the provision of public goods. It is known that the criterion of Pareto efficiency (i.e., the so-called Samuelson condition) alone is unable to uniquely determine the optimal level of public goods in general when individuals are heterogeneous. ${ }^{6}$ A social welfare function is typically introduced to pin it down in such situations. However, this approach may be arbitrary in our context since different social welfare functions as a rule point to different optimal levels of public goods. The advantage of the quasilinear form is that it enables us to stick to the criterion of Pareto efficiency and, at the same time, uniquely determine the optimal level of public goods even in the case of heterogeneous people.

The stylized tax system considered in tax competition models is the proportional capital income tax. To incorporate the regional government function of income redistribution, we extend the stylized tax system from the proportional to the linear capital income tax with a uniform lump-sum grant. That is, the revenue collected from capital taxation in each region is used not only to provide the regional public service, $g$, but also to offer a uniform lump-sum grant, $a$, to each individual in the region. Thus the tax system involved consists of two parameters: a marginal tax rate $t$ and a lump-sum grant $a$. The tax system pays the lump-sum grant or "demogrant" $a$ to each individual in a region, and finances the lump-sum payment and the cost of public good provision by imposing the marginal tax rate $t$ on all capital employed in the region. This redistributive tax system is referred to as a "demogrant policy" in Browning and Johnson (1984) and Ballard (1988). ${ }^{7}$

The government budget constraint in each region implies:

$$
g_{i}+N a_{i}=t_{i} k_{i} \forall i
$$

\footnotetext{
${ }^{5}$ See, for example, Besley and Coate (2003) and Batina and Ihori (2005). As in Wilson (1986) and Zodrow and Mieszkowski (1986), we focus on the fiscal externality generated by mobile tax bases, leaving out the spillover effects of public services across regions for simplicity.

${ }^{6}$ See Varian (1992, p. 419)

${ }^{7}$ The redistribution through the demogrant policy may be criticized for being unrealistic in that transfer receipts include the rich as well as the poor. Browning and Johnson (1984), however, emphasize that only the net effect of the taxes and transfers is crucial for redistribution. They provide evidence that the the demogrant policy can have distributional implications similar to those resulting from the entire actual tax and transfer system.
} 
On the other hand, the individual budget constraint implies:

$$
c_{i j}=(1 / N)\left[f\left(k_{i}\right)-\left(r+t_{i}\right) k_{i}\right]+r \bar{k}_{i j}+a_{i} \forall i j
$$

where $f\left(k_{i}\right)-\left(r+t_{i}\right) k_{i}$ is the wage rate in region $i$. By assumption, individual $j$ in region $i$ supplies $1 / N$ units of labor, $\bar{k}_{i j}$ units of capital, and receives an $a_{i}$ amount of the lumpsum grant.

\section{Analysis}

This section analyzes the individually preferred policy and the policy formation within each region.

Consider individual $j$ in region $i$ who owns $\bar{k}_{i j}$ units of capital. Given $g_{-i}$ and $t_{-i}$, the individually preferred public service $g_{i}$ and tax policy $t_{i}$ satisfy:

$$
\left(g_{i}\left(\bar{k}_{i j}\right), t_{i}\left(\bar{k}_{i j}\right)\right)=\arg \max _{g_{i}, t_{i}}\left\{c_{i j}+v\left(g_{i}\right)\right\} \quad \forall i
$$

where $g_{i}$ and $c_{i j}$ follow (4) and (5), respectively. From (1)-(2) and the budget constraint (4), the lump-sum grant $a_{i}$ will be determined residually once $g_{i}$ and $t_{i}$ are chosen. ${ }^{8}$ The first-order conditions for program (A) with respect to $g_{i}$ and $t_{i}$ are given by:

$$
\begin{aligned}
& \frac{\partial u_{i j}}{\partial g_{i}}=-(1 / N)+v^{\prime}\left(g_{i}\right)=0 \quad \forall i \\
& \frac{\partial u_{i j}}{\partial t_{i}}=\frac{\partial c_{i j}}{\partial t_{i}}=0 \quad \forall i
\end{aligned}
$$

where $v^{\prime}\left(g_{i}\right)$ is the marginal value of the public service.

\subsection{Individually Preferred Level of Public Good Provision}

(6) immediately yields:

$$
N \cdot v^{\prime}\left(g_{i}\right)=1 \forall i
$$

which is the Samuelson condition for the optimal provision of public goods. This result arises because, given $t_{i}, t_{-i}$ and hence $k_{i}$, the marginal rate of transformation (MRT) between $g_{i}$ and $a_{i}$ equals $1 / N$ (see (4)) while the marginal rate of substitution (MRS)

\footnotetext{
${ }^{8}$ Note that the lump sum grant determined residually may not be positive under some parameter values of our model. As pointed out by Inman (1987, pp. 731-732), the possibility of a negative lump sum grant in the linear income tax highlights the tension between two goals of an economy: efficiency and equity. Providing public goods more or less has to do with correcting market failures. This efficiency part of government activities may crowd out redistributive spending so much so that the democratically chosen level of redistributive government activity may become zero or even negative. Although theoretically interesting, we interpret our findings mostly in the more realistic case where the equilibrium lump sum grant is positive.
} 
between $g_{i}$ and $a_{i}$ equals $v^{\prime}\left(g_{i}\right)$ (see this by substituting (5) in the utility function); and each individual equates MRS with MRT if she is decisive.

(6-1) uniquely determines the first-best level of public goods, $g^{F}$. The finding $g_{i}\left(\bar{k}_{i j}\right)=g^{F}$ for all $i j$ gives rise to our first main result:

Proposition 1. Suppose that the tax system in effect is a linear capital income tax with a lump-sum grant. Then tax competition results in an outcome in which all heterogeneous individuals concur with each other on the first-best provision of public goods.

This result is in stark contrast to a fundamental result in the tax competition literature that interregional tax competition for mobile capital generates fiscal externalities and hence tends to result in an undersupply of public goods in a region (see the Introduction).

To understand more about Proposition 1, let us suppose that the demogrant policy is absent so that $a_{i} \equiv 0$ in (4)-(5). In the absence of the demogrant policy, program (A) will be replaced by:

$$
\tilde{t}_{i}\left(\bar{k}_{i j}\right)=\arg \max _{t_{i}}\left\{c_{i j}+v\left(g_{i}\right)\right\} \quad \forall i
$$

and the first-order conditions (6)-(7) will be replaced by:

$$
\frac{\partial u_{i j}}{\partial t_{i}}=\frac{\partial c_{i j}}{\partial t_{i}}+v^{\prime}\left(g_{i}\right) \frac{\partial g_{i}}{\partial t_{i}}=0 \quad \forall i
$$

Using (B-1) and (3)-(5) with $a_{i} \equiv 0, \tilde{t}_{i}\left(\bar{k}_{i j}\right)$ in program (B) gives:

$$
\frac{\partial \tilde{t}_{i}\left(\bar{k}_{i j}\right)}{\partial \bar{k}_{i j}}=\frac{(1 / n)}{\partial^{2} u_{i j} / \partial t_{i}^{2}}<0 \quad \forall i
$$

where $\partial^{2} u_{i j} / \partial t_{i}^{2}<0$ is required by the second-order conditions. The result of (B-2) indicates that the lower the share of capital owned by an individual, the higher the tax rate preferred by the individual. This result is intuitive. In the absence of the demogrant policy, redistribution between the rich and the poor can still take place through sharing the cost of the public good differently. As a result, the rich prefer a lower tax rate while the poor prefer a higher tax rate. Using (3)-(5) with $a_{i} \equiv 0$ also yields:

$$
\frac{\partial c_{i j}}{\partial t_{i}}=-\left(1-\frac{1}{n}\right) \frac{k_{i}}{N}-\frac{1}{n} \bar{k}_{i j}<0 \quad \forall i
$$

where the first RHS term represents the tax-induced change in labor income (the same negative effect across heterogeneous individuals) while the second RHS term represents the tax-induced change in capital income (varied negative effects across heterogeneous individuals). Raising $t_{i}$ will reduce the individual capital income received through the effect of (3-1) and increase "capital flight" through the effect of (3-2). Raising $t_{i}$ will also reduce the individual labor income received because labor and capital are complementary in production. (B-3) implies from (B-1): 


$$
\frac{\partial g_{i}}{\partial t_{i}}>0 \quad \forall i
$$

Putting (B-2) and (B-4) together, we see that the lower the share of capital owned by an individual, the higher will be the level of public good provision preferred by the individual.

However, once the demogrant policy is available as in program (A), redistribution between the rich and the poor can be achieved through the "demogrant" directly (see more elaboration later). As a result, it is no longer necessary to redistribute income indirectly through sharing the cost of public good provision. Putting it differently, heterogeneous individuals face different personalized marginal costs of public good provision in program (B), whereas they all face the same marginal cost of public good provision in program (A). The difference can be seen by comparing (B-1) with (6). This explains why all heterogeneous individuals concur with each other on the first-best provision of public goods in our model.

\subsection{Individually Preferred Tax Rates}

Given $g_{i}=g^{F}$, it is assumed that $\partial^{2} u_{i j} / \partial t_{i}{ }^{2}<0$ so that the second-order conditions are met and there is a unique $t_{i}\left(\bar{k}_{i j}\right)$ satisfying (7).

Using (3) and given that $k_{i}=\bar{k}_{i}$ in a symmetric Nash equilibrium, (7) leads to 9 :

$$
(n-1) \varepsilon_{i} \tau_{i}=1-\frac{S_{i j}}{(1 / N)} \forall i
$$

where $\tau_{i} \equiv t_{i} /\left(r+t_{i}\right)$ (the ad valorem tax rate in region $i$ ), $s_{i j} \equiv \bar{k}_{i j} / \bar{k}_{i}$ (the share of capital owned by individual $j$ in region $i$ ), and $\varepsilon_{i} \equiv-\left[\partial k_{i} / \partial\left(r+t_{i}\right)\right]\left[\left(r+t_{i}\right) / k_{i}\right]$ (the elasticity of demand for capital with respect to the before-tax rate of return in region $i$ ). In (8), each individual trades off the marginal redistributive benefit from taxation (in the form of the deviation between her own capital share $s_{i j}$ and the region's mean capital share $1 / N$ ) against the marginal distortionary cost of taxation (in the form of a tax-induced outflow of capital $\left.(n-1) \varepsilon_{i} \tau_{i}\right)$. The individually preferred capital tax rate results from the balancing of this tradeoff. Note that individuals who own capital shares higher than the region's mean share would like to subsidize capital $\left(t_{i}<0\right)$, while individuals who own capital shares lower than the region's mean share would like to tax capital $\left(t_{i}>0\right)$. Only those individuals whose capital share happens to be the region's mean share would like to neither subsidize nor tax capital $\left(t_{i}=0\right)$.

\subsection{Political Equilibrium}

Obviously, different individuals would like to impose different tax rates if they are decisive. There are several possible ways to pin down tax rates in political equilibrium

\footnotetext{
${ }^{9}$ Technically, there will be a corner solution in the case of $n=1$ so that (8) may not hold as an equality.
} 
(see Persson and Tabellini, 2000). For simplicity, we consider a primitive but transparent way within our model.

From the first-order conditions (7), we have:

$$
\frac{\partial\left(\partial u_{i j} / \partial t_{i}\right)}{\partial t_{i}} d t_{i}+\frac{\partial\left(\partial c_{i j} / \partial t_{i}\right)}{\partial \bar{k}_{i j}} d \bar{k}_{i j}=0 \forall i
$$

From (3)-(5), we have:

$$
\frac{\partial c_{i j}}{\partial t_{i}}=\frac{1}{n}\left(\frac{k_{i}}{N}-\bar{k}_{i j}\right)+\frac{t_{i}[1-(1 / n)]}{N f^{\prime \prime}} \forall i
$$

Since $\partial\left(\partial c_{i j} / \partial t_{i}\right) / \partial \bar{k}_{i j}=-(1 / n)$ by $(10),(9)$ leads to

$$
\frac{\partial t_{i}\left(\bar{k}_{i j}\right)}{\partial \bar{k}_{i j}}=\frac{(1 / n)}{\partial^{2} u_{i j} / \partial t_{i}^{2}}<0 \quad \forall i
$$

which implies that the lower the share of capital owned by an individual, the higher is the tax rate preferred by the individual. This result is intuitive because redistribution from the rich to the poor now takes place through sharing the cost of the lump-sum grant differently. The reasoning behind this result is similar to that behind (B-2). In fact, one can show that $\left(\partial a_{i} / \partial t_{i}\right)>0$ in equilibrium (see Lemma 3), which together with (11) implies that the lower the share of capital owned by an individual, the higher will be the level of demogrant preferred by the individual.

Note that the redistributive incentives of the poor are qualified in the presence of tax competition since (11) depends on the number of competing regions $n$ as well. In particular, it is observed that the rich and the poor will concur with each other on the tax policy if $n \rightarrow \infty$. This is so because, from (3), a change in the tax rate will not affect the after-tax rate of return on capital but will only affect the common labor income once $n \rightarrow \infty$.

By the assumption that $\partial^{2} u_{i j} / \partial t_{i}^{2}<0$, the preferences of individuals qua voters exhibit single-peakedness over tax rates $t_{i}$. Since $t_{i}\left(\bar{k}_{i j}\right)$ is monotonic in $\bar{k}_{i j}$ according to (11), the individual preferences for $t_{i}$ induce a preference ordering for $\bar{k}_{i j}$. This induced preference obviously exhibits single-peakedness over capital endowments $\bar{k}_{i j}$. Then, by invoking the median voter theorem, we arrive at:

Lemma 1. The lower the share of capital owned by an individual, the higher is the tax rate preferred by the individual. The decisive voter in political equilibrium is the median voter, that is, the individual who owns a median share of $\bar{k}_{i}$, denoted by $s_{i j}^{m}$.

This has a conventional flavor since it agrees with a standard result of political competition: the median voter is decisive in determining policy.

Employing Lemma 1 and using (8), we have in political equilibrium:

$$
(n-1) \varepsilon_{i} \tau_{i}=1-\frac{s_{i j}^{m}}{(1 / N)} \forall i
$$


Since positively skewed distributions of capital income are typically observed in the real world, we shall impose the inequality $s_{i j}^{m}<1 / N$. This then implies from (12) that $\tau_{i}>0$ in political equilibrium.

\section{4. "Increased” Interregional Tax Competition}

It is interesting to observe the presence of $n$, the number of competing regions, in (12). When $n=1$ (i.e., there is no tax competition or the economy is closed), the marginal distortionary cost of taxation (the left-hand side of (12)) is equal to zero since $k_{i}=\bar{k}_{i}$ holds all the time. The balancing of the tradeoff is completely dominated by the marginal redistributive benefit from taxation (the right-hand side of (12)). As a result, the equilibrium tax rate will be as high as possible. On the other hand, when $n \rightarrow \infty$ (i.e., a small open economy in which the after-tax rate of return on capital is beyond the control of individual regions), the marginal distortionary cost of taxation approaches infinity. The balancing of the tradeoff is completely dominated by the marginal distortionary cost of taxation (the left-hand side of (12)). As a result, the equilibrium tax rate will be as low as possible. We consider the general case where $1<n<\infty$ in the following.

Given $g_{i}=g^{F}$, the first-order conditions (7) give ${ }^{10}$ :

$$
\frac{\partial\left(\partial u_{i j} / \partial t_{i}\right)}{\partial t_{i}} d t_{i}+\frac{\partial\left(\partial c_{i j} / \partial t_{i}\right)}{\partial n} d n=0 \quad \forall i
$$

Note from $(10)$ that $\partial\left(\partial c_{i j} / \partial t_{i}\right) / \partial n=\left(1 / n^{2}\right)\left[\bar{k}_{i j}-\left(k_{i} / N\right)+\left(t_{i} / N f^{\prime \prime}\right)\right]$, and hence Eq. (13) leads to

$$
\frac{\partial t_{i}\left(\bar{k}_{i j}\right)}{\partial n}=\frac{-\left(1 / n^{2}\right)\left[\bar{k}_{i j}-\left(\bar{k}_{i} / N\right)+\left(t_{i} / N f^{\prime \prime}\right)\right]}{\partial^{2} u_{i j} / \partial t_{i}^{2}} \forall i
$$

where we have utilized $k_{i}=\bar{k}_{i}$ in a symmetric Nash equilibrium. This result implies that $\left(\partial t_{i}\left(\bar{k}_{i j}\right) / \partial n\right)<0$ if $\bar{k}_{i j}<\bar{k}_{i} / N$ or, equivalently, $s_{i j}<1 / N$. Since $s_{i j}^{m}<1 / N$, we have from Lemma 1:

Lemma 2. $\left(\partial t_{i}\left(\bar{k}_{i j}\right) / \partial n\right)<0$ holds in equilibrium in our economy.

That is, the equilibrium tax rate chosen by the decisive median voter is monotonically decreasing in the number of competing regions.

Using (3)-(5), (7) can be expressed as:

$$
\frac{\partial c_{i j}}{\partial t_{i}}=-\left[\left(1-\frac{1}{n}\right) \frac{k_{i}}{N}+\frac{\bar{k}_{i j}}{n}\right]+\frac{\partial a_{i}}{\partial t_{i}}=0 \quad \forall i
$$

Thus, from (15), we also have:

Lemma 3. $\left(\partial a_{i} / \partial t_{i}\right)>0$ holds in equilibrium in our economy.

\footnotetext{
${ }^{10}$ We treat $\mathrm{n}$ as a continuous variable, as in Seade (1980).
} 
Lemma 3 confirms the intuition that a rational individual will not pursue taxation so much so that an increase in the tax rate reduces the lump-sum grant received: $\left(\partial a_{i} / \partial t_{i}\right) \leq 0$.

Putting Lemmas 2-3 together yields our second main result:

Proposition 2. The equilibrium size of the demogrant is monotonically decreasing in the number of competing regions.

As noted in the Introduction, Hoyt (1991) shows that the extent to which public goods are undersupplied is monotonically increasing in the number of competing regions. Regional government activities are confined to public good provision only and the agents are identical in Hoyt's model. Our inclusion of income redistribution as well as public good provision in government activities leads to a dramatic change. In contrast to Hoyt's finding, we show that, regardless of the number of competing regions, all heterogeneous individuals concur with each other on the first-best provision of public goods (Proposition 1); on the other hand, the size of income redistribution (measured by the size of the demogrant) is monotonically decreasing in the number of competing regions (Proposition 2). The tradeoff with more jurisdictions emphasized by Hoyt (1991) is not at a cost of decreasing public service provision, but at a cost of decreasing income redistribution if agents are heterogeneous and more redistribution is desirable.

\subsection{Comparison with Meltzer and Richard (1981)}

In their classical work, Meltzer and Richard (1981) consider a closed economy in which individuals vote over the linear (labor) income tax.

They show that each individual trades off the marginal redistributive benefit from taxation against the marginal distortionary cost of taxation. The individually preferred labor tax rate results from the balancing of this tradeoff. The tradeoff between distortion and redistribution is highlighted in many tax models (say, the celebrated Mirrlees (1971) model) and seems to be the most important feature of the political economy of taxation. In view of this, it is not surprising to find that the mechanism driving both our result and their result is quite similar. However, observe that there is no role for $n$ in the determination of the size of income redistribution in the Meltzer-Richard closed economy, whereas the role of $n$ is important in the determination of the size of income redistribution in our open economy. It is worth noting that the theoretical finding summarized by our Proposition 2 is consistent with some empirical evidence which suggests that the size of regional governments varies inversely with the total number of competing regions. ${ }^{11}$

\footnotetext{
${ }^{11}$ See, for example, Nelson (1987), Eberts and Gronberg (1988) and Zax (1989). Note that we do not incorporate leisure-labor choice into our model. Empirically, it seems hard to recognize the disincentive effect of income taxes on labor supply (Saez, 2002). However, it is very clear that tax competition among regions will significantly affect the allocation of capital. In this sense, it would be more useful to consider this aspect in the analytical framework of an open economy than to investigate the conventional leisure-labor choice in a closed model.
} 


\section{Discussion}

This paper considers the linear tax system $T(k)=-a+t k$ with a lump-sum grant, showing that tax competition results in an outcome in which all heterogeneous individuals concur with each other on the first-best provision of public goods (Proposition 1). One may question the robustness of this result if the tax system is extended from linear to non-linear.

Following Cukierman and Meltzer (1991), a simple non-linear extension takes the form $T^{\prime}(k)=-a+t k+t^{\prime} k^{2}$. Unlike $T(k)$ in which the marginal tax rate is constant in $k$, the marginal tax rate varies with $k$ in $T^{\prime}(k)$. It can be checked that Proposition 1 remains true with the extension from $T(k)$ to $T^{\prime}(k)$. The reason is that MRT (the marginal rate of transformation between $g_{i}$ and $a_{i}$ ) still equals to $1 / N$ with the replacement of $T(k)$ by $T^{\prime}(k)$ and, as a result, (6) still holds. In fact, one can make further extensions of the tax system to, say, $T^{\prime \prime}(k)=-a+t k+t^{\prime} k^{2}+t^{\prime \prime} k^{3}$ or $T^{\prime \prime \prime}(k)=-a+t k+t^{\prime} k^{2}+t^{\prime \prime} k^{3}+t^{\prime \prime \prime} k^{4}$, and show that the conclusion of Proposition 1 remains true with respect to these further extensions.

Given tax rates, an increase in the level of public good provision is effectively financed by a uniform lump-sum tax (a reduction of the demogrant). This is the key to our Proposition 1. As long as the non-linear capital income tax contains a uniform lumpsum grant such as the $a$ term in $T^{\prime}(k), T^{\prime \prime}(k)$ and $T^{\prime \prime \prime}(k)$, the conclusion of Proposition 1 will remain true. ${ }^{12}$

In our model labor is assumed completely immobile and hence the regional population size $N$ remains a constant all the time. This is an important assumption to uphold Proposition 1. However, with some labor mobility, a change in one region's tax-transfer policy might induce individual mobility across regions. Once the regional population size is endogenously determined, Proposition 1 may no longer hold. In such a case the traditional Tiebout result might hold: People live together in a homogeneous region and the redistributive policy becomes less important.

Given tax rates, the RHS term of (4) will be given as well. Since an increase in the level of public good provision is effectively financed by a uniform lump-sum tax, the exercise of (6) basically represents a resource re-allocation between the public good provision and the lump-sum grant in terms of the LHS terms of (4). As long as the cost associated with labor mobility is high enough to dominate the net benefits or costs resulting from this resource re-allocation, individuals will not move across regions in response to the resource re-allocation. In such a situation, the regional population size $N$ can de facto be treated as a constant even if allowing for some labor mobility.

In our setting, capital is assumed a perfectly mobile factor while labor an interregional immobile factor. This setting is to capture the fact that these factors have different degrees of mobility in the real world. How our Proposition 1 may be modified in the presence of some capital immobility and/or some labor mobility is an issue worth further study.

\footnotetext{
${ }^{12}$ The availability of a lump-sum grant is crucial to our result. If income redistribution is done in the form of a different instrument without a lump-sum grant or in the form of income-contingent transfers, the conclusion of Proposition 1 would not hold.
} 


\section{References}

Ballard, C.L., 1988, “The Marginal Efficiency Cost of Redistribution”, American Economic Review, 78, 1019-1033.

Batina, R.G. and T. Ihori, 2005, Public Goods: Theories and Evidence (Berlin: SpringerVerlag).

Besley, T. and S. Coate, 2003, "Centralized versus Decentralized Provision of Local Public Goods: A Political Economy Approach", Journal of Public Economics, 87, 2611-2637.

Browning, E.K. and W.R. Johnson, 1984, "The Trade-off between Equality and Efficiency", Journal of Political Economy, 92, 175-203.

Cukierman, A. and A.H. Meltzer, 1991, “A Positive Theory of Progressive Income Taxation”, in: A.H. Meltzer, A. Cukierman, and S.F. Richard, eds., Political Economy (Oxford: Oxford University Press).

Davies, J.B. and A.F. Shorrocks, 2000, "The Distribution of Wealth", in: A. Atkinson and F. Bourguignon, eds., Handbook of Income Distribution (Amsterdam: North-Holland).

Eberts, R.W. and T.J. Gronberg, 1988, "Can Competition among Local Governments Constrain Government Spending?", Federal Reserve Bank of Cleveland Economic Review, 1, 2-9.

Fuest, C., B. Huber, and J. Mintz, 2005, "Capital Mobility and Tax Competition", Foundations and Trends in Microeconomics, 1, 1-62.

Haufler, A., 2001, Taxation in a Global Economy (Cambridge: Cambridge University Press). Hoyt, W.H., 1991, "Property Taxation, Nash Equilibrium, and Market Power", Journal of Urban Economics, 30, 123-131.

Inman, R.P., 1987, "Markets, Governments, and the "New" Political Economy", in: A.J. Auerbach and M. Feldstein, eds., Handbook of Public Economics, Vol. II (Amsterdam: North-Holland).

Meltzer, A. and S. Richard, 1981, “A Rational Theory of the Size of Government”, Journal of Political Economy, 89, 914-927.

Mirrlees, J.A., 1971, “An Exploration in the Theory of Optimum Income Taxation”, Review of Economic Studies, 38, 175-208.

Nelson, M.A., 1987, "Searching for Leviathan: Comment and Extension", American Economic Review, 77, 198-204.

Oates, W.E., 1972, Fiscal Federalism, (New York: Harcourt Brace Jovanovich).

Persson, T. and G. Tabellini, 2000, Political Economics: Explaining Economic Policy (Cambridge, MA: MIT Press).

Saez, E., 2002, “Optimal Income Transfer Programs: Intensive versus Extensive Labor Supply Response”, Quarterly Journal of Economics, 117, 1039-1073.

Seade, J., 1980, "On the Effects of Entry", Econometrica, 48, 479-489.

Tanzi, V. and L. Schuknecht, 2000, Public Spending in the $20^{\text {th }}$ Century (Cambridge: Cambridge University Press).

Varian, H.R., 1992, Microeconomic Analysis, Third edn., (New York: Norton \& Company).

Wellisch, D., 2000, Theory of Public Finance in a Federal State (Cambridge: Cambridge University Press).

Wildasin, D.E., 1988, "Nash Equilibrium in Models of Fiscal Competition", Journal of Public Economics, 35, 229-240. 
Wilson, J.D., 1986, “A Theory of Interregional Tax Competition”, Journal of Urban Economics, 19, 296-315.

Wilson, J.D., 1999, "Theories of Tax Competition", National Tax Journal, 52, 269-304.

Wilson, J.D. and D.E. Wildasin, 2004, "Capital Tax Competition: Bane or Boon", Journal of Public Economics, 88, 1065-1091.

Zax, J.S., 1989, “Is There a Leviathan in Your Neighborhood?", American Economic Review, $79,560-567$.

Zodrow, G.R. and P.M. Mieszkowski, 1986, "Pigou, Tiebout, Property Taxation, and the Under-provision of Public Goods", Journal of Urban Economics, 19, 356-370. 